\title{
Species of plasmodium (P. Falciparum and P. Vivax) involved in children with malaria: An experience from a tertiary childcare hospital.
}

1. MBBS, FCPS (Pediatric Medicine) Senior Registrar Pediatric Medicine The Children's Hospital \& ICH, Multan.

2. MBBS, FCPS (Pediatric Medicine) Senior Registrar Paediatric Medicine The Children's Hospital \& ICH, Multan.

3. MBBS, FCPS (Paediatric Medicine) Associate Professor Paediatric Medicine

The Children's Hospital \& ICH, Multan.

4. MBBS

House Office

Holy Family Hospital, Rawalpindi

Correspondence Address:

Dr. Asim Khurshid

Department of Paediatric Medicine

The Children's Hospital \& ICH, Multan. asimkhurshiddr@gmail.com

Article received on:

09/07/2020

Accepted for publication: 24/09/2020

\section{Muhammad Shahzad Maqsood', Safdar Hussain ${ }^{2}$, Asim Khurshid ${ }^{3}$, Sana Waqar}

ABSTRACT... Objective: To find out different species of plasmodium (P. falciparum and P. vivax) involved in children with malaria at a tertiary childcare hospital. Study Design: Descriptive, Cross-sectional study. Setting: Department of Paediatric Medicine, The Children's Hospital and Institute of Child Health, Multan. Period: October 2019 to March 2020. Material \& Methods: A total of 281 cases of either gender, aged 1 to 12 years and patients with malaria were enrolled. A special template was designed to record study information. Venous blood as five $\mathrm{ml}$ sample was drawn and dispatched to institutional laboratory for ICT malaria, complete blood count and giemsa stain smear and observed under light microscope. Data analysis was performed employing SPSS version 24.0. Results: Out of a total of 281 cases, $177(63.0 \%)$ were male ande $104(37.0 \%)$ female. Mean age of study participants was $4.29 \pm 2.48$ years. A total of 135 $(48.0 \%)$ children belonged to rural areas and $197(70.1 \%)$ had monthly family income $<25000$ rupees. Mean duration of illness was $4.21 \pm 2.12$ days. Previous history of use of anti-malarial drugs was noted in $62(22.1 \%)$ of our study cases. Plasmodium falciparum was observed in $52(18.5 \%)$ cases and plasmodium vivax in 229 (81.5\%). Conclusion: Plasmodium vivax is predominantly more prevalent in our population as compared with plasmodium falciparum in children with malaria. Plasmodium falciparum and plasmodium vivax were significantly linked with age and disease duration. Malaria was noted to be more prevalent among poor families living in slum areas having inadequate sanitation facilities.

Key words: Malaria, Plasmodium Falciparum, Plasmodium Vivax.

Article Citation: Maqsood MS, Hussain S, Khurshid A, Waqar S. Species of plasmodium ( $P$ Falciparum and $P$. Vivax) involved in children with malaria: An experience from a tertiary childcare hospital. Professional Med J 2021; 28(7):997-1001. https://doi.org/10.29309/TPMJ/2021.28.07.5551

\section{INTRODUCTION}

Malaria is considered a major public health issue globally and around 3 billion people are thought to be at risk of acquiring malarial infections. In 2018, around 228 million cases of malaria were estimated globally by "World Health Organization". It was also calculated that Malaria was responsible for causing 405000 deaths whereas children aged below 5 years were the most commonly affected age group, accounting for nearly $67 \%$ of all mortalities around the world. ${ }^{1}$ Malaria is declared endemic in about 103 countries, making it one of the most common and widespread human parasite disease. Malaria ranks $1^{\text {st }}$ affecting socioeconomic and public health in tropical and sub-tropical regions while Sub-Saharan African region is the most affected part. ${ }^{2-4}$
Pakistan stands in the top 10 countries in terms of incidence of malaria and reports around 50000 deaths annually due to this public health problem. Malaria is considered an important public health issue obstructing socio-economic development in Pakistan. ${ }^{5}$ Most commonly found species of plasmodium are P. falciparum, P. vivax, P. ovale, P. knowlesi and $P$. malariae and can cause infection in humans. High grade fever, headache, shivering as well as vomiting are some of the most commonly found symptoms of malaria. Symptoms usually appear after 10-15 days following bite of infective mosquito. ${ }^{6}$

In Pakistan, P. falciparum and P. vivax are most commonly found. In local findings, Yaseen $M$ et $\mathrm{al}^{5}$ noted P. vivax and P. falciparum to be present in $76 \%$ and $24 \%$ children respectively whereas 
Shaikh AS et $\mathrm{al}^{7}$ noted $\mathrm{P}$. falciparum and $\mathrm{P}$. vivax to affect $65.2 \%$ and $28.5 \%$ of children. Factors contributing to this increase were nominated as increasing chloroquin resistance, warmer autumn and chronic decline in vector control activities. ${ }^{8}$

There are limited number of studies on this topic in our country and no study is conducted in South Punjab in last 5 years. Moreover these studies have reported variable findings, as some studies reported P. falciparum as a major culprit while others have reported P. Vivax. ${ }^{5,7}$ these findings point towards the fact regarding geographic distribution and natural adaptation of the plasmodium in different geographic subsets. So we planned to conduct this study in our population to know which species of plasmodium are pre-dominant. The aim of this study was to find out different species of plasmodium (P. falciparum and $P$. vivax) involved in children with malaria at a tertiary childcare hospital.

\section{MATERIAL \& METHODS}

This descriptive, cross-sectional study was conducted at The Department of Paediatric Medicine, The Children's Hospital and Institute of Child Health, Multan, from October 2019 to March 2020. Approval from "Institutional Ethical Committee" was taken.

Sample size of 281 cases was calculated using formula " $n=z^{2} p q / d^{2}$ ", Where $z=1.96, p=24 \%^{5}$ (frequency of plasmodium falciparum), $q=100-p$, $d=5 \%$ at $95 \%$ confidence level.

A total of 281 cases of either gender, aged 1 to 12 years and patients with malaria having fever $\geq 101^{\circ} \mathrm{F}$ assessed on thermometer plus positive test with ICT malaria, were enrolled. Children as known patients of congenital heart disease, or having coagulopathy, bleeding disorders (e.g. hemophilia, or diagnosed patients of brain tumors, tuberculosis meningitis, viral or bacterial encephalitis and multiple sclerosis were not enrolled. Those children who reported history of anti-malarial drugs intake in the past 48 hours were also excluded. Informed consent was sought from parents/guardians of all children.
A special template was designed to record study information. Venous blood as five $\mathrm{ml}$ sample was drawn and dispatched to institutional laboratory for ICT malaria, complete blood count and giemsa stain smear and observed under light microscope as described in Table number $1 .{ }^{9}$

Data analysis was performed employing SPSS version 24.0. Mean and standard deviation was calculated for age whereas qualitative variables like gender, age groups, anti-malarial drugs intake, residential status, monthly family income and frequency of P. falciparum and P. vaviax were represented as frequencies and percentages. Effect modifiers like age, residential status, family income, gender, disease duration, intake of antimalarial drugs (before 48 hours) were controlled by stratification. Post stratification chi-square test was applied to see their effect on outcome taking p-value $<0.05$ as significant.

\section{RESULTS}

Out of 281 children, 177 (63.0\%) were male and 104 (37.0\%) female. Mean age was 4.29 2.48 years, ranging from 1-12 years. Mean age among male and female children was $5.17 \pm 2.50$ years and $2.80 \pm 1.56$ years respectively $(p<0.0001)$. Most children, 240 (85.4\%) were less than 7 years of age, $146(52.0 \%)$ belonged to urban areas, 197 (70.1\%) had monthly family income less than 25000 rupees. Mean duration of illness recorded as $4.21 \pm 2.12$ days and $198(70.5 \%)$ had duration of illness $<5$ days. Previous history of use of antimalarial drugs was noted in $62(22.1 \%)$ children. Table number 2 is showing characteristics of children in the present study.

P. falciparum was observed in $52(18.5 \%)$ cases while P. vivax in 229 (81.5\%).

P. falciparum and P. vivax were stratified with regards to gender, age, residential status, monthly family income, duration of illness and previous history of use of anti-malarial drugs as shown in Table number 3 . Children aged less than 7 years as well as those who had disease duration of less than 5 days had significant association with P. falciparum while age more than 7 years as well as disease duration of more than 5 days was 
significantly associated with P. vivax $(p<0.0001)$.

\section{DISCUSSION}

Among humans, most threatening complications are caused by P. falciparum and P. vivax whereas $P$. falciparum is known to be more virulent than

Table-I. Giemsa Stain Smear Criteria ${ }^{9}$

\begin{tabular}{|l|l|l|l|l|}
\hline \multicolumn{1}{|c|}{ Parasite } & \multicolumn{2}{|c|}{ Ring } & \multicolumn{1}{|c|}{ Trophozoite } & \multicolumn{1}{|c|}{ Schizont } \\
\hline $\begin{array}{l}\text { Plasmodium } \\
\text { Falciparum }\end{array}$ & $\begin{array}{l}\text { Delicate cytoplasm;1-2 } \\
\text { small chromating dots }\end{array}$ & $\begin{array}{l}\text { Compact } \\
\text { cytoplasm }\end{array}$ & $\begin{array}{l}\text { Mature, dark } \\
\text { pigments } \\
\text { clumped in one } \\
\text { mass. }\end{array}$ & $\begin{array}{l}\text { Crescent shape, } \\
\text { Chromatin in a single } \\
\text { mass; dark pigment } \\
\text { mass }\end{array}$ \\
\hline Plasmodium vivax & $\begin{array}{l}\text { Large cytoplasm; large } \\
\text { chromatin dot }\end{array}$ & $\begin{array}{l}\text { Large ameboid } \\
\text { cytoplasm; } \\
\text { yellowish brown } \\
\text { pigment }\end{array}$ & $\begin{array}{l}\text { Large filling RBC, } \\
\text { yellowish brown, } \\
\text { coalesced } \\
\text { pigment. }\end{array}$ & $\begin{array}{l}\text { Oval shaped, compact; } \\
\text { chromatin compact, } \\
\text { eccentric; scattered } \\
\text { brown pigment }\end{array}$ \\
\hline
\end{tabular}

the other malarial parasites. ${ }^{10}$ Around $80 \%$ of the cases and more than $90 \%$ of deaths are credited to P. falciparum in Africa. Contrary to Sub-Saharan African region, P. vivax is responsible for more than half of all malarial infections in the Asian and Latin American region. ${ }^{11}$

\begin{tabular}{|c|c|c|c|}
\hline \multicolumn{2}{|l|}{ Characteristics } & \multirow{2}{*}{$\begin{array}{c}\text { Frequency } \\
177\end{array}$} & \multirow{2}{*}{$\begin{array}{c}\text { Percentage } \\
63.0\end{array}$} \\
\hline Gondor & Male & & \\
\hline Gender & Female & 104 & 37.0 \\
\hline Age Groups (years) & $>7$ & 41 & 14.6 \\
\hline \multirow{2}{*}{ Residential Status } & Rural & 135 & 48.0 \\
\hline & Urban & 146 & 52.0 \\
\hline Monthly Family Income (Rupees) & $>25000$ & 84 & 29.9 \\
\hline \multirow{2}{*}{ Disease Duration (days) } & $<5$ & 198 & 70.5 \\
\hline & $>5$ & 83 & 29.5 \\
\hline \multirow{2}{*}{ Previous History of use of anti-malarial drugs } & Yes & 62 & 22.1 \\
\hline & No & 219 & 77.9 \\
\hline
\end{tabular}

Table-II. Characteristics of children in the present study $(n=281)$

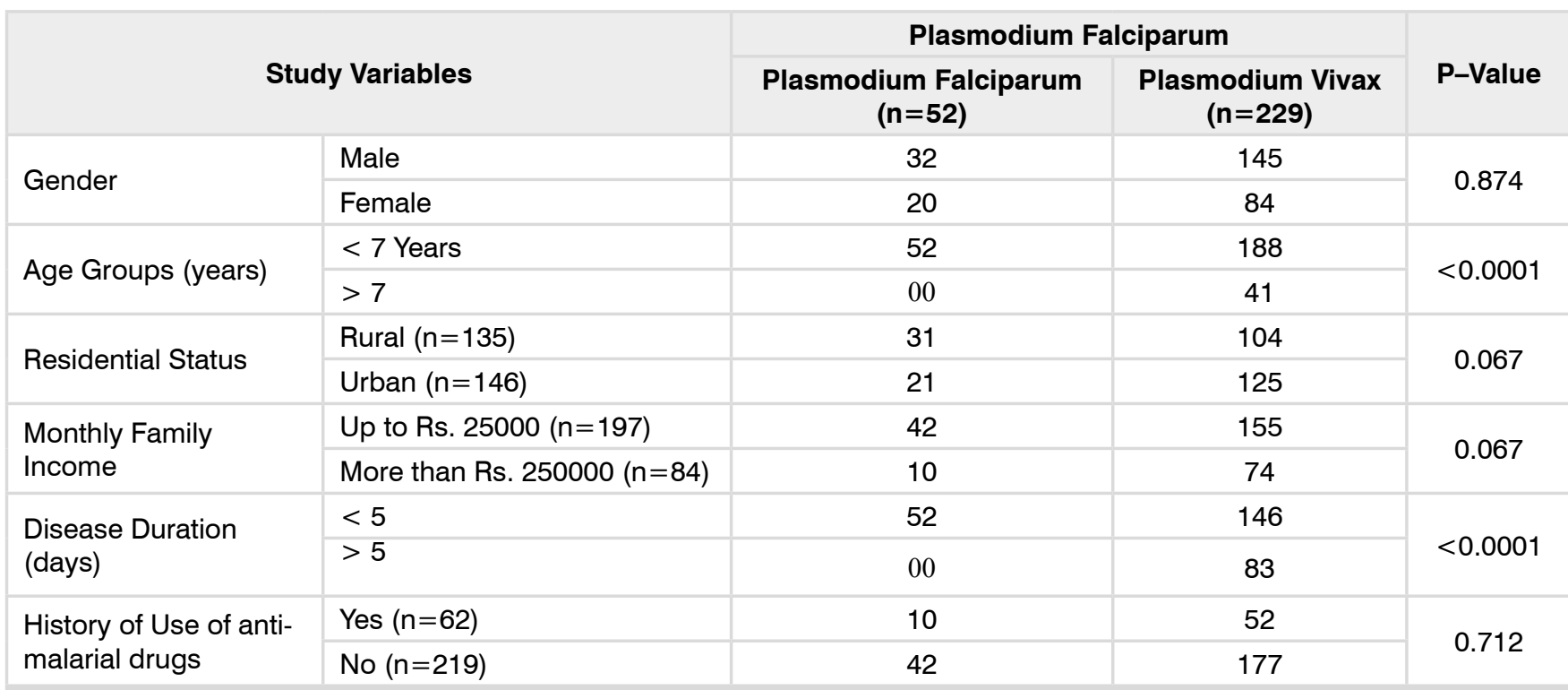

Table-III. Stratification of plasmodium species with regards to study variables $(n=281)$ 
In the current study, $63.0 \%$ of patients were male. Male predominance by previous researchers among pediatric malaria cases have been found. Khatak AM et al $^{12}$ in an earlier local study reported male predominance similar to our findins. Leghari AR et $\mathrm{al}^{13}$ from Bahawalpur in 2104 also noted $56 \%$ of the study participants in their laboratory surveillance data as males. Yasinzai MI et al ${ }^{14}$ also showed that majority of the study participants $(76 \%)$ with malarial infections were male.

We noted overall mean age as $4.29 \pm 2.48$ years. Mean age among male children was $5.17 \pm 2.50$ years while it was $2.80 \pm 1.56$ years in female children $(p=0.000)$. Most cases, 240 (85.4\%) were aged less than 7 years. A study conducted by Shaikh AS et $\mathrm{al}^{7}$ also reported $70 \%$ of malaria cases to be $<5$ years of age which is quite close to what we recorded. Geleta $\mathrm{G}$ et $\mathrm{al}^{10}$ from Ethiopia estimated mean age of 4.1 years among children with malarial infections.

We had also found that $48.0 \%$ cases belonged to rural areas and $52.0 \%$ belonged to urban areas. Monthly family income of $<25000$ rupees was reported by $70.1 \%$ cases. As we know that people living in slum areas are more prone to have malarial infection while factors like poor sanitation, sewage settings and socioeconomic status further worsens the situation favoring malarial infection. We had noted similar findings. In the present study, mean duration of illness was $4.21 \pm 2.12$ days and $198(70.5 \%)$ had duration of illness $<5$ days. Previous history of use of antimalarial drugs was noted in $22.1 \%$ of our study cases. Shah $\mathrm{H}$ et $\mathrm{al}^{15}$ analyzing local population of KPK noted similar findings.

Different studies have documented $P$. vivax as the predominant causative malarial agent in south Asian countries. P. falciparum was observed in $52(18.5 \%)$ while plasmodium vivax was noted in 229 (81.5\%) of our study cases. From Karachi, P. vivax was noted among $76.0 \%$ and $P$. falciparum in $24.0 \%$ cases by Yaseen $M$ and colleagues. ${ }^{5}$ Shaikh AS et al $^{7}$ reported $65.2 \%$ P. falicparum and $P$. vivax in $28.5 \%$ of the children with malaria from Karachi which is different from our findings. Some others in the past from Sindh Province of Pakistan also reported higher prevalence of $P$. falciparum among cases with malaria which shows that the difference persists among different regions of Pakistan. ${ }^{16-18}$ Findings of Khattak et al ${ }^{91}$ were more aligned to what we found where they noted $86.0 \%$ of the diagnosed cases of malaria to have involvement of P. vivax while remaining $14.0 \%$ had P. falciparum. Other studies in the past from South Punjab have also indicated that $P$. vivax is the more common causative agent for malaria here.13

Our study provides a fresh glimpse about most common malarial causative agents found at a tertiary child healthcare facility of South Punjab. Most of the children with malaria present with fever, rigor or chills, along with anemia and / or splenomegaly so it is recommended that children presenting with these sign and symptoms should have high degree of suspicion for malaria and should be investigated and managed accordingly. We were unable to document commonest modes of presentations among our children. We also did not plan to evaluate seasonal effects of these malarial parasites among studied children which would have given us fruitful insights. Further studies involving different areas of Pakistan should be planned with larger sample size to further confirm the findings of our study.

\section{CONCLUSION}

Plasmodium vivax is predominantly more prevalent in our population as compared with plasmodium falciparum among patients with malaria. Plasmodium falciparum and plasmodium vivax were significantly associated with age and disease duration. Malaria was noted to be more prevalent among poor families living in slum areas having inadequate sanitation facilities.

\section{ACKNOWLEDGEMENT}

The authors would like to thank Muhammad Aamir (Research Consultant, Bahawalpur) for his valuable assistance in statistical analysis of this research.

Copyright@ 24 Sep, 2020. 


\section{REFERENCES}

1. World Health Organization. World Malaria Report 2019. Geneva: World Health Organization; 2019. Available at: https://www.who.int/news-room/fact-sheets/detail/ malaria.

2. Worku L, Damtie D, Endris M, Getie S, Aemero M. Asymptomatic malaria and associated risk factors among school children in Sanja town, Northwest Ethiopia. Int Scholarly Res Notices. 2014; 2014:303269.

3. Fançony C, Gamboa D, Sebastião Y, Hallett R, Sutherland C, Sousa-Figueiredo JC, et al. Various pfcrt and pfmdr1 genotypes of Plasmodium falciparum cocirculate with P. malariae, P. ovale spp., and P. vivax in northern Angola. Antimicrob Agents Chemother. 2012 Oct; 56(10):5271-7.

4. Maltha J, Guiraud I, Kaboré B, Lompo P, Ley B, Bottieau $E$, et al. Frequency of severe malaria and invasive bacterial infections among children admitted to a rural hospital in Burkina Faso. PLoS One. 2014; 9(2):e89103.

5. Yaseen M, Ali NH. Frequency and seasonal distribution of plasmodium falciparum and plasmodium vivax in children in Tertiary hospital Karachi - Pakistan. Int $\mathrm{J}$ Endorsing Health Sci Res. 2015; 3(1):23-5.

6. Kakar Q, Khan MA, Bile KM. Malaria control in Pakistan: new tools at hand but challenging epidemiological realities. East Mediterr Health J. 2010; 16 Suppl:S54-60.

7. Shaikh AS, Memon IA, Khatwani NR, Memon SI, Memon Al, Saleem AF. Clinical spectrum and outcome of children presented with different malarial species in Karachi, Pakistan. Pak Paed J. 2014; 38(2):84-90.

8. Fazil M. The frequency of various human malaria parasite infections at private clinic in Mardan district of Khyber Pakhtunkhwa: A study of 230 cases of Malaria. Pak Paed J. 2013; 37(3):173-6.
9. Alemu M, Tadesse D, Hailu T, Mulu W, Derbie A, Hailu $T$, et al. Performance of laboratory professionals working on malaria microscopy in Tigray, North Ethiopia. J Parasitol Res. 2017; 2017:9064917.

10. Geleta G, Ketema T. Severe malaria associated with plasmodium falciparum and $P$. vivax among Children in Pawe Hospital, Northwest Ethiopia. Malar Res Treat. 2016; 2016:1240962.

11. Arévalo-Herrera M, Lopez-Perez M, Medina L, Moreno A, Gutierrez JB, Herrera S. Clinical profile of Plasmodium falciparum and Plasmodium vivax infections in low and unstable malaria transmission settings of Colombia. Malar J. 2015; 14:154.

12. Khattak AM, Khan J, Batool N, Khan H. The magnitude and pattern of malaria in District Kohat. Gomal J Med Sci. 2013; 11(2):208-11.

13. Leghari AR, Hussain MS, Idris M, Saleem M. Laboratory surveillance of malaria at District Bahawalpur Punjab, Pakistan. J Shaikh Zayed Med Coll. 2014; 5(3):668-70.

14. Yasinzai MI, Kakarsulemankhel JK. Prevalence of human malaria infection in District Ziarat and Sanjavi, Pakistan. Pak J Zool. 2009; 41(6):475-82.

15. Shah H, Khan R, Naz F, Haseeb A, Jan A, Ullah R. Prevalence and distribution of malaria parasites in general population of district Dir Lower, Khyber Pakhtunkhwa, Pakistan. J Entomol Zool Studies. 2016; 4(4):1211-15.

16. Nizamani MA, Kalar NA, Khushk IA. Burden of malaria in Sindh, Pakistan: A two years surveillance report. J Liaquat Uni Med Health Sci 2006; 5(2):76-83.

17. Soomro AA, Shaikh BA, Shams R, Shaikh GS, Pathan $S M$. Slide positivity rate of malaria parasite at Z.A Bhutto laboratory Chandka Medical College Hospital, Larkana. Inf J Pathol 2007; 5(2):89-91.

18. Murtaza G, Memon I, Noorani AK. Malaria Prevalence in Sindh. Med Channel 2004; 10(2):41-42.

\section{AUTHORSHIP AND CONTRIBUTION DECLARATION}

\begin{tabular}{|c|l|l|}
\hline Sr. \# & \multicolumn{1}{|c|}{ Author(s) Full Name } & \multicolumn{1}{|c|}{ Contribution to the paper } \\
\hline 1 & M. Shahzad Maqsood & $\begin{array}{l}\text { Data collection, Data } \\
\text { analysis, Drafting. } \\
\text { Methodology, Literature } \\
\text { review. } \\
\text { Study concept, } \\
\text { Supervision, Proof reading. }\end{array}$ \\
\hline 3 & Safdar Hussain & $\begin{array}{l}\text { Asim Khurshion, Data } \\
\text { interpretation. }\end{array}$ \\
\hline 4 & Sana Waqar & \\
\hline
\end{tabular}

